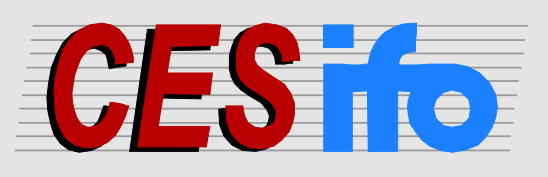

\title{
Working
}

Papers

www.cesifo.org/wp

\section{Investment in Broadband Infrastructure Under Local Deregulation: Evidence from the U.K. Broadband Market}

\author{
Nadine Fabritz \\ Oliver Falck
}

CESIFO WORKING PAPER NO. 4277

CATEGORY 11: INDUSTRIAL ORGANISATION

JUNE 2013

An electronic version of the paper may be downloaded

- from the SSRN website:

- from the RePEc website:

- from the CESifo website:

wWw.SSRN.com

www.RePEc.org

www.CESifo-group.org/wp

\section{CESifo}




\title{
Investment in Broadband Infrastructure Under Local Deregulation: Evidence from the U.K. Broadband Market
}

\begin{abstract}
This paper investigates telecommunication operator investment in broadband infrastructure after local deregulation of the wholesale broadband access market. Using a panel dataset covering all 5,598 exchange areas in the United Kingdom, we exploit regional differences in deregulation following a 2008 reform. Controlling for initial conditions, first-difference estimates show that local deregulation increases local investment in infrastructure by both the incumbent and competitors.
\end{abstract}

JEL-Code: L500, L960.

Keywords: telecommunication, regulation, infrastructure investment, wholesale broadband access, United Kingdom.

Nadine Fabritz

Ifo Institute - Leibniz-Institute

for Economic Research

at the University of Munich

Munich/Germany

fabritz@ifo.de
Oliver Falck

Ifo Institute - Leibniz-Institute

for Economic Research

at the University of Munich

Munich/Germany

falck@ifo.de

June 2013

Comments by Constantin Mang, Ludger Wößmann, seminar participants at the ifo Institute, and representatives of British Telecom are gratefully acknowledged. British Telecom also helped to complete our dataset. We thank Julia Zimmermann for excellent research assistance. Financial support by Deutsche Telekom AG is gratefully acknowledged. 


\section{Introduction}

Traditionally, it was considered necessary to regulate the telecommunication sector so as to foster competition by opening former incumbents' network infrastructure. Years, and in some countries decades, after market liberalization, telecommunication markets have done well and incumbents in many countries face increasing infrastructure-based competition. In this context, regulatory authorities and policymakers are now concerned with designing appropriate incentives that will ensure this positive development continues and that will encourage future investment and innovation in network infrastructure.

Within countries, infrastructure-based competition has developed unequally, with some regions enjoying more competitive markets than others. Many observers therefore argue that national regulators should focus their attention on areas in which competitive markets cannot be sustained (EC, 2008a; Weizsäcker, 2008). As a result, in recent years, a number of European countries have debated - and in some cases introducedgeographically differentiated regulation schemes in the wholesale broadband access (WBA) market. ${ }^{1}$ These schemes allow for deregulation in areas with sufficient infrastructure-based competition. It remains unresolved, both from a theoretical as well as from an empirical perspective, how deregulation of areas with well-developed infrastructure-based competition affects future competitive development (see Stumpf, 2010). To date, there are no clear predictions on future price developments and the ultimate effects on the competitive environment are unknown. Policymakers are thus reluctant to institute deregulation (see, e.g., Bundesnetzagentur, 2010; EC, 2008c).

In this study, we provide an empirical evaluation of the effects of local deregulation in the WBA market on infrastructure investment by the incumbent telecommunication carrier and its competitors. To this end, we make use of a change in the regulatory scheme in the United Kingdom WBA market. In 2008, the U.K. regulator, Ofcom, divided the WBA market into three competition areas. In areas with sufficient infrastructure-based competition, the incumbent (British Telecom) was released from regulation in that specific market. Ofcom applied a set of rules that determine the deregulation of exchange areas, inter alia, based on the number of principal operators (POs), which are large operators with extensive coverage in the British WBA market, and the size of the local retail market.

Our data are from the Internet platform Samknows (Samknows, 2007, 2012). Samknows is a not-for-profit website that provides information on broadband availability in the United Kingdom. It furthermore reports detailed information at the exchange level on

\footnotetext{
${ }^{1}$ For an overview, see Tables A1 and A2 in the Appendix.
} 
key characteristics such as exchange location, regulatory status, the names of local loop unbundling (LLU) operators present in an exchange, actual and prospective fiber-to-thecurb (FTTC) status, the number of premises served by an exchange, and broadband availability via cable. We merge these exchange-level data with ward-level sociodemographic characteristics.

We measure broadband providers' investment incentives in response to local deregulation on two dimensions. First, we investigate the number of LLU operators in an exchange to capture the extent of infrastructure-based competition the incumbent faces in local markets. LLU operators made large investments in installing and maintaining their own infrastructure. Second, we analyze the incumbent's infrastructure investments by its roll out of FTTC technology, which enables higher transfer rates and allows the incumbent to differentiate itself from the competitors. We concentrate on these measures, since increasing infrastructure-based competition is the preferred goal of regulatory authorities. It is favored over service-based competition since it is sustainable and increases consumer choice while lowering consumer prices in the long run (Bourreau and Dogan, 2004; Woroch, 2002).

We quantity the effects of deregulation with a first-difference approach in which we compare the development of regulated and deregulated areas between 2007 and 2012. Since deregulation decisions are based on the competitive situation in an exchange area, regulated and deregulated areas must differ in their initial (i.e., prior to the reform) competitive situation and other local characteristics. We therefore additionally control for the initial competitive situation and other local characteristics.

One concern is that our basic specification might capture a "self-fulfilling prophecy," which arises due to the fact that Ofcom's deregulation decision depends not only on actual, observed investment, but also on its forecast for local investments by POs. Therefore, our basic specification might not only capture investment due to deregulation, but also investment that would have occurred in any case (and, in fact, led to the deregulation).We cannot observe Ofcom's forecasts, but a change in the deregulation rules between the first review in 2008 and the second review in 2010 allows us to distinguish similar exchange areas with and without forecasts.

We find positive, economically important effects of deregulation on infrastructure-based competition. The number LLU operators increases more in deregulated exchange areas than in regulated areas between 2007 and 2012. We also quantify the part of these investments that cannot stem from Ofcom forecasts and therefore capture the pure deregulation effect. Furthermore, deregulation increased British Telecom's investment in 
FTTC infrastructure: in deregulated areas, British Telecom is significantly more likely to roll out FFTC.

The remainder of the paper is organized as follows. Section 2 describes in more detail the WBA market and the deregulation process in the United Kingdom. Section 3 introduces our data. Section 4 presents our estimation strategy, basic results, and various robustness specifications. Section 5 concludes.

\section{Institutional Setting}

\subsection{Wholesale Broadband Access}

WBA refers to a wholesale broadband market in which an entrant with limited own infrastructure buys transmission services from the incumbent with access to the end-users' premises. These entrants' own infrastructure only reaches certain points of presence (PoP) in the backbone network. At the PoP, entrants hand over data transmission to the incumbent. In the beginning, mandated wholesale broadband access was considered to create competition in the broadband market since market entrants could offer products on the retail market without owning infrastructure that actually connects to end-users. Over the last several years, however, market entrants have increasingly begun to invest in their own infrastructure. Their own networks typically expands down to the exchange where they connect to the copper-based local loops that link every premise to the exchange, a process known as local loop unbundling (LLU). The local loops are owned by the incumbent, who is required to grant access on regulated conditions. The infrastructure-based competitors thus can offer not only services to end-users, but also wholesale broadband access. Figure 1 displays the structure of the WBA market. Copper-based local loops are viewed as an essential facility and the regulation of access to them is not under debate. Deregulation of the WBA market, in contrast, is widely discussed throughout Europe, at least for areas with increasing infrastructure-based competition (OECD, 2010; Kiesewetter, 2011).

\subsection{The Process of Local Deregulation in the United Kingdom}

In the United Kingdom, the WBA market traditionally has been regulated on a national basis, but in 2008, geographically differentiated regulation of the WBA market came into effect. The European Commission supported Ofcom's decision since ex ante regulation should be relaxed when infrastructure-based competition becomes sufficiently developed (EC, 2007). 
British Telecom's local exchange areas were chosen as the relevant geographical unit. Broadband service providers make their supply and infrastructure investment decisions at the exchange level, since each exchange covers a certain geographical area and therefore defines the local customer base. Ofcom grouped all exchange areas into three categories based on their competitive situation. ${ }^{2}$ Categories 1 and 2 remain regulated, but the incumbent British Telecom was released from regulation in Category 3 areas.

Category 1 is comprised of exchange areas where British Telecom is the only operator. Category 2 contains exchange areas in which some competition has developed. These are exchange areas with two or three principal operators (POs) actually present or forecast to be so. Also in Category 2 are exchange areas with four POs, which includes one forecast PO (i.e., three are actually present), but that serve less than 10,000 premises. Besides British Telecom and Virgin Media (the cable operator), six LLUs with a coverage of more than 45 percent of U.K. premises were considered to be POs. ${ }^{3}$ Exchange areas with four or more POs and exchange areas with three POs and at least one more forecast, but that serve more than 10,000 premises, form Category 3. Table A3 in the Appendix summarizes the criteria underlying the deregulation decision in 2008.

In its 2010 revision of WBA market regulation, Ofcom considered the 10,000 premises rule redundant and introduced a new criterion for deregulation. In addition to the number of POs, British Telecom's market share had to be lower than 50 percent, the standard threshold at which significant market power can be assumed according to Commission guidelines (Ofcom, 2010). Table A4 in the Appendix summarizes the criteria underlying the 2010 market definitions. Figure 2 shows the geographical distribution of deregulated exchange areas in the United Kingdom as of 2010, mapping exchange areas that were deregulated in 2008 and 2010.

\footnotetext{
${ }^{2}$ In addition, a fourth market was defined in the Hull area, where KCOM, a local provider, was the only operator. This area contains 14 exchange servers and covers 0.7 percent of U.K. premises. Due to data limitations, exchanges owned by KCOM are excluded from this analysis.

${ }^{3}$ These are Sky, O2, Orange, Cable\&Wireless, Tiscali, and the TalkTalk group. Virgin Media counts as a $\mathrm{PO}$ if its coverage of premises in the respective market is at least 65 percent.
} 


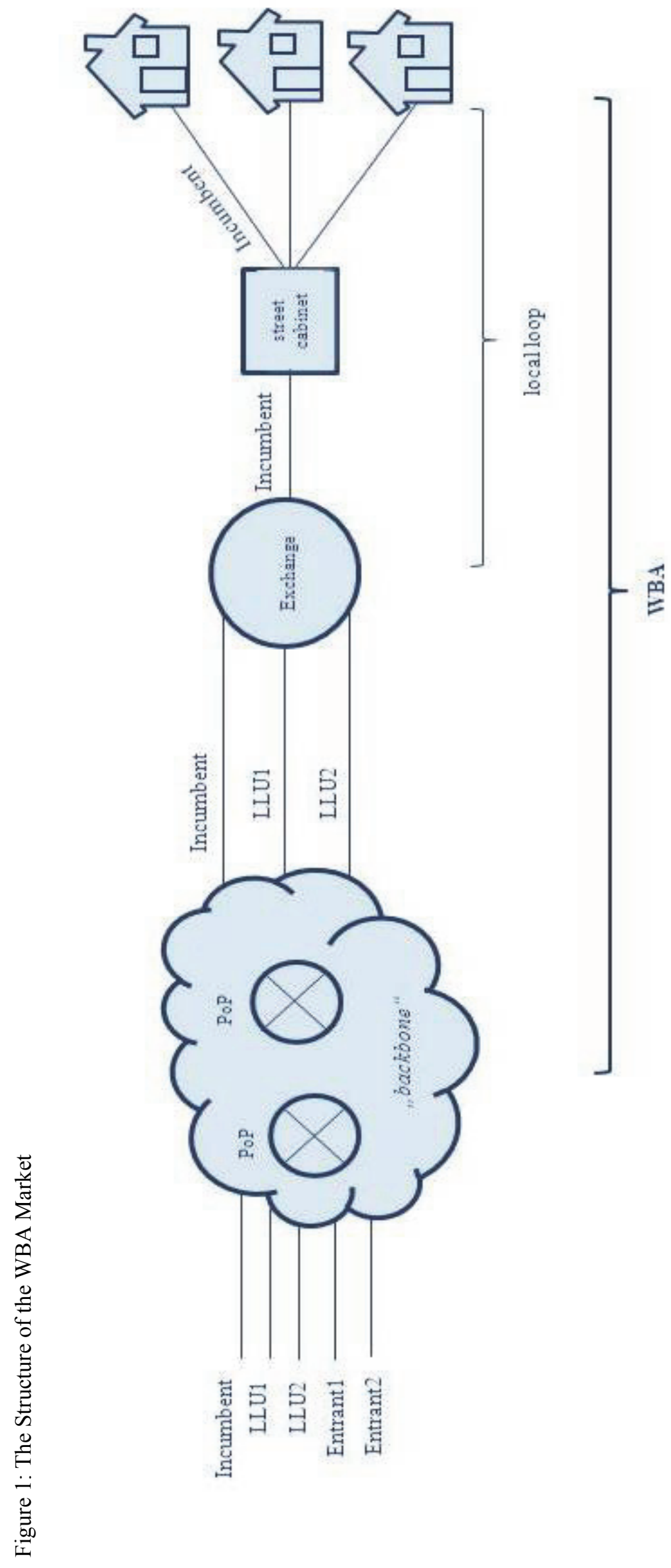

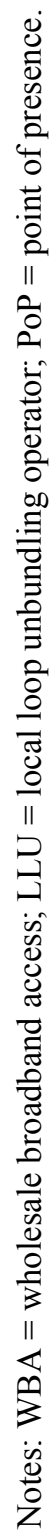


Figure 2: Geographic Distribution of Deregulated Exchange Areas in the United Kingdom

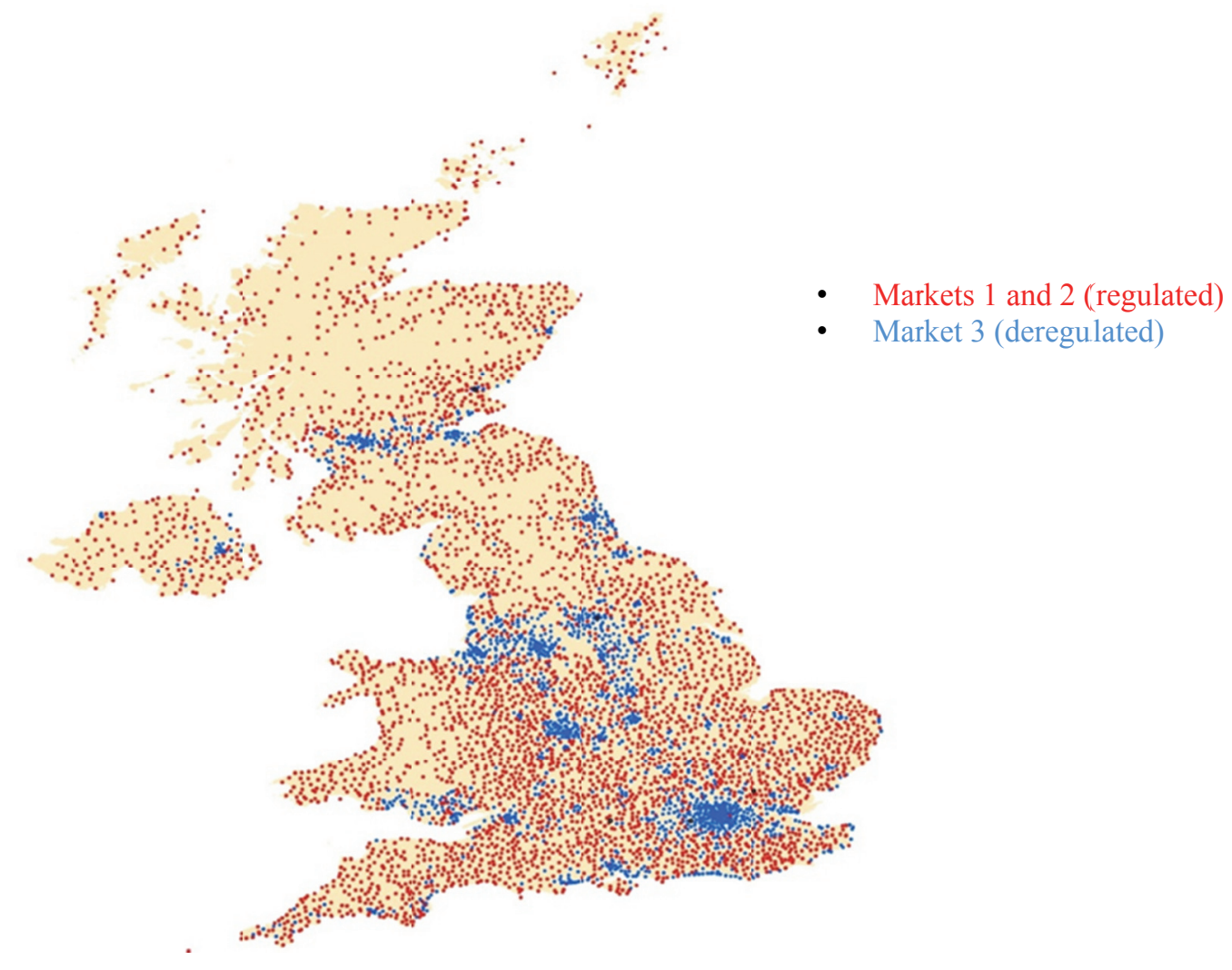

Source: own representation based on Samknows data

\section{Exchange-Level Data and Regional Characteristics}

Our data are from the Internet platform Samknows, a not-for-profit website that was originally founded to provide broadband speed tests to the general public. The website provides comprehensive information on the local competitive environment, such as the LLU operators present in an exchange, the enabled technologies that determine the broadband speed, and the number of premises served by an exchange. The website is continuously updated and we observe cross-sections or "snapshots" of all 5,598 exchange areas at two points in time, December 2007 and November 2012.

Our measure for infrastructure investment by the incumbent's competitors is the number of LLU operators present in an exchange. Table A5 in the Appendix lists the LLU operators along with their national coverage in both years. The list of LLU operators in the U.K. market is not fully congruent over time due to the highly dynamic nature of the broadband market. The six largest firms in terms of infrastructure coverage were considered POs in 2007 and are relevant for the deregulation process. In 2012, there were in effect only four operators. In 2010, PO Orange handed its LLU network back to BT. In 
the same year, POs Tiscali and TalkTalk merged. Despite this fact, Samknows still reports the two firms separately and so we observe five POs rather than four. ${ }^{4}$ Our measure for the incumbent's infrastructure investment is a binary indicator that takes the value 1 when FTTC has been enabled by the incumbent British Telecom or will be enabled in the exchange by 2013. As Table 1 shows, in 2007 none of the exchange areas had FTTC, since the technology had not yet been introduced to the broadband market. By 2012, 25 percent of exchange areas had this infrastructure or had it installed in the near future. Table 1 further reveals that the number of LLU operators present in an exchange area increased considerably from, on average, 1.24 LLU operators in 2007 to 1.80 LLU operators in 2012. The incumbent BT and the cable operator Virgin Media count as POs, but they are not considered as LLU operators and consequently are not included in these numbers.

Table 1: Descriptive statistics of exchange- and ward-level characteristics, by year

\begin{tabular}{|c|c|c|c|c|}
\hline & \multicolumn{2}{|c|}{2007} & \multicolumn{2}{|c|}{2012} \\
\hline & mean & std. dev. & mean & std. dev. \\
\hline \multicolumn{5}{|l|}{ Exchange-level characteristics } \\
\hline \# of exchange areas & 5,598 & & 5,598 & \\
\hline \# LLU operators & 1.24 & $(2.27)$ & 1.80 & $(2.57)$ \\
\hline FTTC enabled & 0 & $(0)$ & 0.25 & $(0.44)$ \\
\hline Deregulated & 0 & $(0)$ & 0.28 & $(0.45)$ \\
\hline \# of premises & $4,852.03$ & $(6,984.94)$ & $4,852.03$ & $(6,984.94)$ \\
\hline Broadband via cable available & 0.24 & $(0.42)$ & 0.24 & $(0.42)$ \\
\hline \multicolumn{5}{|l|}{$\underline{\text { Ward-level characteristics }}$} \\
\hline Population share working age & 0.60 & $(0.05)$ & 0.62 & $(0.05)$ \\
\hline Population density (per km²) & 956.10 & $(1,997.30)$ & 984.99 & $(2,064.33)$ \\
\hline Claimant count share (working age) & 0.02 & $(0.01)$ & 0.03 & $(0.02)$ \\
\hline
\end{tabular}

Note: Standard deviations (std. dev.) in parentheses.

We also obtain our main explanatory variable - the WBA deregulation status - from Samknows. ${ }^{5}$ Each exchange is assigned to one of the three regulatory markets. In 2008 , 1,193 out of 5,598 exchange areas were deregulated. After Ofcom's 2010 revision, another 348 exchange servers were deregulated, while seven were reregulated. Overall, 28 percent of exchange areas were deregulated in 2012, which corresponds to 78.2 percent of U.K. premises.

\footnotetext{
${ }^{4}$ Orange's exit as an LLU and the merger of Tiscali and TalkTalk do not affect the regulatory decision since these events took place after Ofcom's revision in 2010.

${ }^{5}$ Since we base our estimates on data from Samknows and not from Ofcom directly, small deviations from the figures published in Ofcom $(2008,2010)$ occur.
} 
We derive cable operator presence in the exchange area from Samknows in order to account for composition of the local infrastructure competition. Even though cable operators do not offer WBA services during the period of analysis, they exert indirect competitive pressure via the retail market. Broadband connections realized via cable infrastructure are in direct competition with FTTC lines since they offer similar broadband speeds. Lastly, we obtain from Samknows the size of the local market an exchange serves, reported as the number of premises connected to the exchange. The number of premises comprises all residential as well as commercial premises connected to an exchange.

Samknows reports the exchange areas' geographic locations via their postcodes. With this information we are able to geo-code the exchange areas and assign them to wards. We thus merge the exchange-level data with regional characteristics at the ward level. The information on ward boundaries in Great Britain is from Edina (2012); ward boundaries for Northern Ireland are made available from the Northern Ireland Statistics and Research Agency (2012a). As of 2011, the United Kingdom had 9,523 electoral wards with an average population of 5,500. The working-age population and the claimant count serve as proxies for local income and demand for broadband, respectively. Population density is a measure for supply since it indicates the unit costs of providing broadband. In densely populated areas, a provider can reach a larger customer base with the same amount of infrastructure investment than it can in a sparsely populated area.

The working-age population is defined as the population share of the male inhabitants aged 16-64 and the female inhabitants aged 16-59. Population density is calculated as ward inhabitants per $\mathrm{km}^{2}$. The population data are obtained from the U.K. national statistical offices: the Office for National Statistics (2012), which covers England and Wales, the Scottish Neighbourhood Statistics (2012), and the Northern Ireland Statistics and Research Agency (2012b). The claimant count is obtained from NOMIS (2012), the Office for National Statistics' database on U.K.-wide labor market statistics. This measure is available at the ward-level and counts the unemployed people claiming Jobseeker's Allowances in a particular month. We construct the annual average, which is expressed as the share of claimant count in the working-age population. Descriptive statistics for these variables are reported in Table 1. 


\section{The Effect of Local Deregulation on Investment Behavior}

\subsection{Estimation Strategy and Sample Restriction}

We estimate the effect of local deregulation of the British WBA market on the investment behavior of both the incumbent and its competitors in a first-difference model conditional on initial exchange and ward characteristics:

$$
\Delta \mathrm{Y}_{\mathrm{i}, 2007-12}=\alpha+\beta \mathrm{D}_{\mathrm{i}, 2008 / 10}+\mathrm{X}_{\mathrm{i}, 2007} \gamma^{\prime}+\Delta \mathrm{X}_{\mathrm{i}, 2007-12} \kappa^{\prime}+\varepsilon_{\mathrm{i}}
$$

$\Delta \mathrm{Y}$ is the change in the outcome of interest between 2007 (i.e., before deregulation) and 2012 (i.e., after deregulation). Our outcomes of interest are the development of the number of LLU operators in the exchange $i$ and the incumbent's FFTC status, both of which serve as indicators of the intensity of infrastructure-based competition in the respective exchange areas. $\mathrm{D}$ is a dummy variable that equals unity if the exchange is no longer regulated in 2008 or 2010. $\mathrm{X}$ is a matrix of exchange characteristics (number of premises, number of LLU operators, and cable presence) and local characteristics at the ward-level (working-age population share, population density, claimant count population share, dummies for England, Wales, Scotland, and Northern Ireland) in 2007. We control for these initial values to account for the fact that regulated and deregulated exchange areas were already different before deregulation and thus might exhibit differing trends even if deregulation had not taken place. For example, with the unbundling of the local loop in the United Kingdom in 2001, all exchange areas started without LLUs. By 2007, some areas had achieved a considerable level of competition and therefore were deregulated, whereas other areas experienced no competition. Therefore, the matrix X also contains the "number of LLU operators in 2007." $\Delta X$ is a matrix of all local characteristics at the ward level expressed in changes between 2007 and 2012. $\varepsilon$ is an error term.

$\beta$ is the coefficient of interest. It gives us the association between local deregulation and either the number of LLU operators present in the exchange or the FTTC status of the incumbent conditional on initial values of exchange and (changes in) ward characteristics. The effect of local deregulation is estimated consistently under the assumption that investments at regulated and deregulated exchange areas would have developed in parallel in the absence of deregulation given the initial structural differences. To ensure comparability between regulated and deregulated areas regarding their characteristics in 2007, we also estimate our model for subgroups of exchange areas that are very similar in their initial conditions. 
Figure 3 shows the probability of an exchange being deregulated based on number of premises served. The figure indicates that if the exchange has less than 2,000 premises, its probability of being deregulated is practically zero, whereas if it serves more than 23,000 premises, the probably is unity. In contrast, we find strong variation in the probability of local deregulation of the WBA market for exchange areas having a number of premises served that falls between these two values. We thus restrict our analysis to those 2,276 exchange areas that serve between 2,000 and 23,000 premises.

Table 2 shows descriptive statistics for the exchange areas included in our analysis. Descriptive statistics are reported before deregulation took place in 2007 , and by regulatory status in 2008/2010. Out of the 2,276 exchange areas, 928 (41 percent) are deregulated by $2008 / 2010$. The table reveals that regulated and deregulated exchange areas are not directly comparable due to large structural differences between them that already existed before deregulation. Deregulated exchange areas serve on average about 8,000 premises more than regulated exchange areas. Initial competition is more pronounced in deregulated exchange areas than in regulated exchange areas as deregulated exchange areas initially have, on average, 4.17 LLU operators more than regulated areas and they are located in denser wards than are regulated exchange areas.

Figure 3: The Probability of Deregulation by Premises

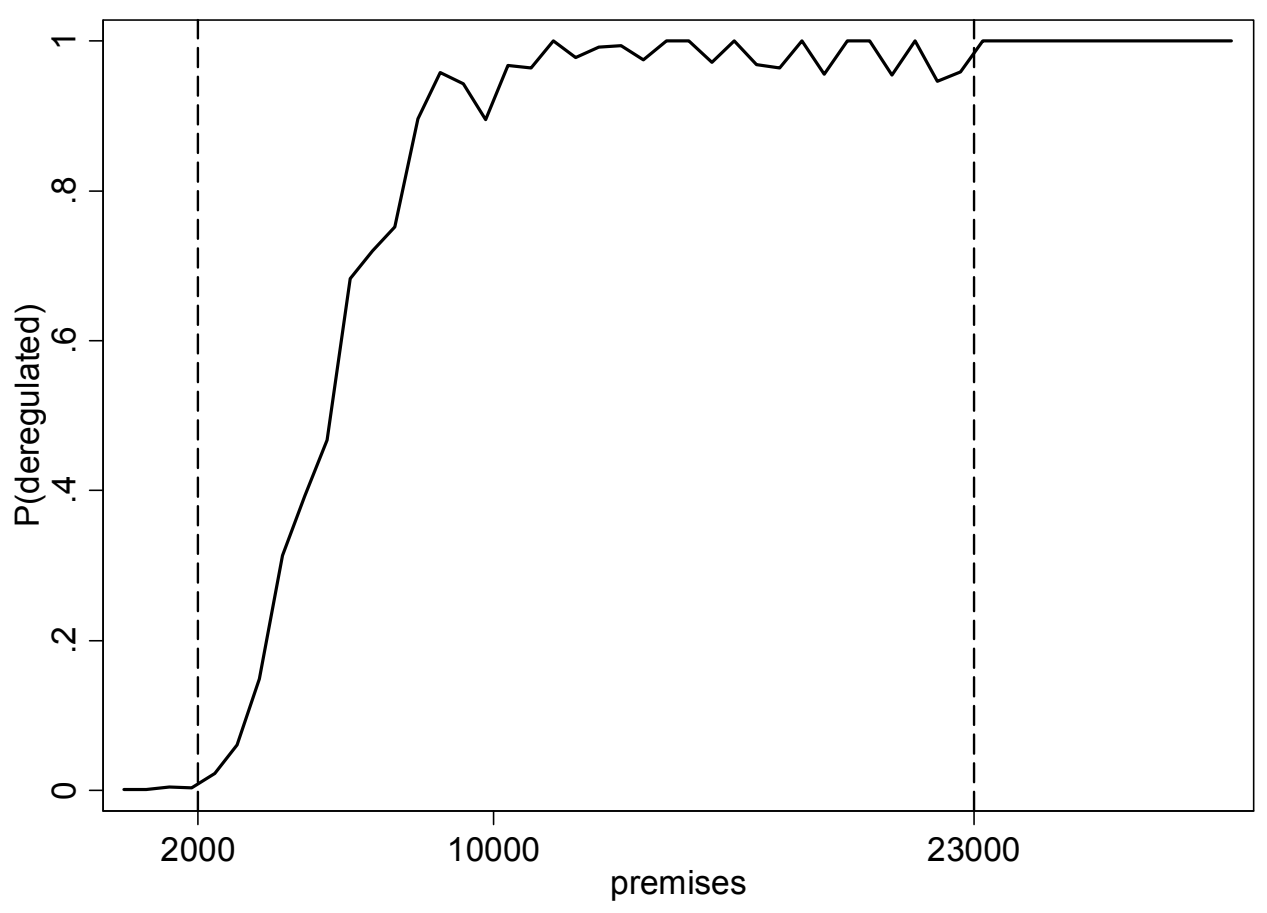


Table 2: Descriptive statistics in 2007 , by regulatory status

\begin{tabular}{lrrr}
\hline \hline & regulated & dereg. & $\mid$ difference $\mid$ \\
\hline Exchange-level characteristics & & & \\
No. of exchange areas & 928 & 1,348 & \\
No. of LLU operators & 0.09 & 4.26 & $4.17^{* * *}$ \\
No. of principal operators & 1.13 & 5.29 & $4.16^{* * *}$ \\
FTTC enabled & 0 & 0 & \\
No. of premises & $3,832.80$ & $11,790.90$ & $7,958.1^{* * *}$ \\
Cable via broadband & 0.16 & 0.70 & $0.54^{* * *}$ \\
& & & \\
Ward-level characteristics & & & \\
Population share working age & 0.59 & 0.62 & $0.03^{* * *}$ \\
Population density (per km ${ }^{2}$ ) & 587.7 & $2,705.4$ & $2,117.7^{* * *}$ \\
Claimant count share (working age) & 0.015 & 0.024 & $0.009^{* * *}$ \\
\hline
\end{tabular}

Notes: Descriptive statistics for exchange areas with 2,000 to 23,000 premises.

$* * * \mathrm{p}<0.01$

\subsection{The Effect of Local Deregulation on Investment}

Table 3 shows the results for our first-difference specification. The first column reports results for changes in the number of LLU operators and the second column for the FTTC status of British Telecom. Both regressions include the initial number of LLU operators, the number of premises served by the exchange, and cable presence. This information is from the year 2007. We also include ward characteristics for the year 2007 and changes in ward characteristics from 2007 to 2012. Robust standard errors are reported in parentheses. The results suggest that, on average, deregulated exchange areas have 1.1 (rounded) LLU operators more than regulated exchange areas. FTTC rollout is on average 26.2 percentage points more likely in deregulated exchange areas.

The control variables have the expected signs and magnitudes. The initial value of LLU operators is negative in Column (1), which might indicate a saturation effect: with an increasing amount of initial infrastructure-based competition, it is less profitable for additional competitors to become LLUs. In contrast, the effect is positive in Column (2), which denotes the incumbent's reaction: in regions with a priori well-developed infrastructure competition, BT is more likely to invest in FTTC. This infrastructure upgrade might be a reaction to increased competition from the LLUs since BT can use FTTC to differentiate itself from its competitors by offering a higher quality product (in terms of bandwidth). As expected, the cable variable is negative in both estimations. In areas in 
which broadband is already available via cable, LLU operators and the incumbent find it less economically worthwhile to invest. In a sense, the cable variable could be interpreted as reflecting the cable operator's first-mover advantage. Finally, the premises variable clearly reveals that broadband provider investment is driven by local demand as they are more likely to invest in larger markets.

Table 3: Basic results

\begin{tabular}{|c|c|c|c|c|}
\hline & $\begin{array}{c}(1) \\
\Delta \mathrm{LLU}\end{array}$ & $\begin{array}{c}(2) \\
\Delta \text { FTTC }\end{array}$ & $\begin{array}{c}(3) \\
\Delta \mathrm{LLU}\end{array}$ & $\begin{array}{c}(4) \\
\Delta \mathrm{FTTC}\end{array}$ \\
\hline Deregulated (in 2008 or 2010) & $\begin{array}{c}1.055 * * * \\
(0.072)\end{array}$ & $\begin{array}{c}0.262 * * * \\
(0.028)\end{array}$ & $\begin{array}{c}1.199 * * * \\
(0.096)\end{array}$ & $\begin{array}{c}0.199 * * * \\
(0.035)\end{array}$ \\
\hline \# LLU (in 2007) & $\begin{array}{c}-0.476^{* * *} \\
(-0.023)\end{array}$ & $\begin{array}{c}0.041 * * * \\
(0.007)\end{array}$ & & \\
\hline LLU dummies (in 2007) & & & yes & yes \\
\hline Broadband via cable (in 2007) & $-0.168 * * *$ & $-0.117 * * *$ & $-0.191 * * *$ & $-0.102 * * *$ \\
\hline Premises (in 1,000s) & $\begin{array}{c}(-0.051) \\
0.079 * * * \\
(0.009)\end{array}$ & $\begin{array}{c}(-0.021) \\
0.023 * * * \\
(0.003)\end{array}$ & $\begin{array}{c}(-0.053) \\
0.079 * * * \\
(0.009)\end{array}$ & $\begin{array}{c}(-0.022) \\
0.023 * * * \\
(0.003)\end{array}$ \\
\hline$\Delta$ Regional characteristics & yes & yes & yes & yes \\
\hline Regional characteristics in 2007 & yes & yes & yes & yes \\
\hline Country dummies & yes & yes & yes & yes \\
\hline \# of exchanges & 2,276 & 2,276 & 2,276 & 2,276 \\
\hline R-squared & 0.333 & 0.394 & 0.348 & 0.4 \\
\hline
\end{tabular}

Notes: First-differences estimations on the exchange level. Exchange areas with 2,000 to 23,000 premises are included in the regressions. Columns (3) and (4) include a full set of dummies for every starting value of LLU operators. Robust standard errors in parentheses.

$* * * \mathrm{p}<0.01,{ }^{* *} \mathrm{p}<0.05,{ }^{*} \mathrm{p}<0.1$

To this point, we have imposed a linear relationship between the outcome of interest and the initial exchange and ward characteristics. This assumption of linearity between the outcome of interest and the initial exchange and ward characteristics becomes especially hazardous when we estimate the effect on the change in the number of LLU operators and additionally control for the number of LLU operators in 2007. Our specification implies that an increase in the initial number of LLU operators from, e.g., one to two operators will have the same effect on changes in the number of LLU operators as would an increase from four to five initial LLU operators.

To see whether this may affect our results, we next relax the assumption of a linear relationship between the outcome of interest and the initial exchange characteristics. We do 
this by replacing the initial number of LLU operators in our basic regressions with a full set of dummies for every starting value of LLU operators. The results are shown in Columns (3) and (4) of Table 3. Deregulated exchange areas, on average, now have 1.2 LLU operators more than regulated exchange areas. FTTC rollout is on average 19.9 percentage points more likely in deregulated exchange areas. The estimated effects of local deregulation are comparable to the effects found in the first specification, indicating that the functional form of the first specification does not compromise the validity of our results.

\subsection{Ensuring Comparability Between Regulated and Deregulated Exchange Areas}

To better compare regulated and deregulated areas regarding their initial situations, we now create subsamples of regulated and deregulated exchange areas, for each of which the two areas have very similar initial conditions. Our first subsample consists of regulated and deregulated exchange areas that are "statistical twins" in terms of their ward characteristics. Statistical twins are matched, using the propensity score matching method, on working-age population share, population density, and claimant count population share. As a nonparametric estimation technique, propensity score matching allows us to impose a common support in the sample. With common support, only exchange areas with similar propensity scores, i.e., with similar probabilities of deregulation, are compared with each other. The results are shown in Table 4 and suggest that deregulated exchange areas have, on average, between 0.84 and 0.95 LLU operators more than regulated exchange areas, depending on the matching algorithm. FTTC rollout is on average between 14.3 and 23.3 percentage points more likely in deregulated exchange areas. Overall, the matching only slightly decreases the magnitude of the deregulation effects presented in Table 3, suggesting that differences in initial ward characteristics, which are the basis of our matching approach, do not distort our results. 


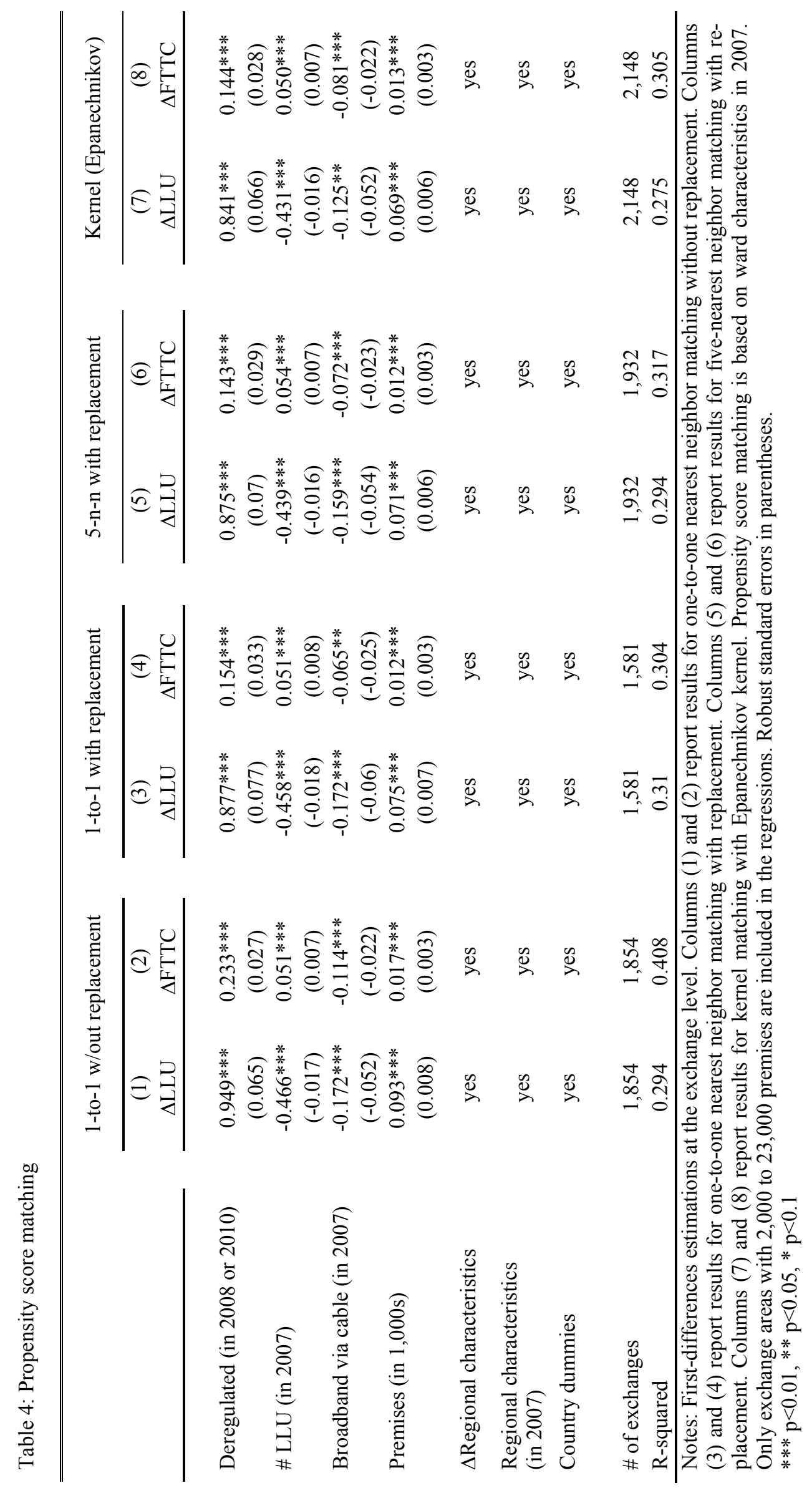


Our second subsample approach concentrates on the 451 exchange areas with three or four POs present in 2007. These exchange areas are comparable in terms of their initial competitive situation but differ in the probability of being deregulated according to Ofcom's rules. Note that in 2008, Ofcom deregulated only those exchange areas with four POs or exchange areas with three POs if at least one more PO was forecast and the number of premises served by the exchange is greater than 10,000. The results of this subsample estimation are shown in Columns (1) and (2) of Table 5. On average, deregulated exchange areas have 0.61 LLU operators more than regulated exchange areas. FTTC rollout is on average 17.1 percentage points more likely in deregulated exchange areas.

Even though in the subsample of exchanges with three or four POs in 2007 deregulated and non-deregulated exchanges are comparable in terms of initial competitive situation, they might still differ in terms of market size. Deregulated exchange areas serve on average larger markets. Therefore, in a next step, we restrict the sample of exchanges with three or four POs in 2007 to exchange areas serving fewer than 10,000 premises so as to achieve better comparability between regulated and deregulated exchange areas. The results are shown in Columns (3) and (4) of Table 5. Again, deregulation shows a positive effect, and the coefficients are significant at the 5 and 10 percent level for the number of LLU operators and FTTC deployment, respectively. The effect on the number of LLU operators decreases to 0.42 , while the effect on FTTC deployment remains relatively stable and decreases only slightly to 16.1 percentage points.

The results in Table 5 imply that controlling for the initial competitive situation in an exchange area is not sufficient to guarantee the validity of the common trend assumption when considering the effect on BT's competitors. Restricting the subsample to ex ante more similar exchange areas thus provides more credible estimates of the deregulation effect.

\subsection{Removing Principal Operator Forecasts}

The last subsample is interesting from another perspective, too: in its deregulation decisions, Ofcom considers unobserved forecasts of principal operators' future investments. Thus, our estimation results of the effect of deregulation on the number of LLU operators might simply reflect, to some extent, Ofcom's forecasts as a self-fulfilling prophecy: that is, an exchange area is expected to have a positive development in the future and is consequently deregulated. If the expected investments occur in the future, they will be attributed to deregulation in the results presented in the previous section, even though they would also have occurred in the absence of deregulation, giving rise to endogeneity bias of the deregulation coefficient. 
To distinguish between the effect of deregulation and these forecast effects, we use the fact that Ofcom incorporated the criterion that exchange areas had to exceed 10,000 premises for deregulation in 2008, but then dispensed with this requirement in 2010. This change leads to the situation that in our subsample of exchanges areas with three or four POs and less than 10,000 premises, 120 premises were deregulated in 2008 because they had four POs. Out of the remaining 221 exchange areas that were not deregulated by 2008,179 were deregulated in 2010. Since the 10,000 premises criterion was dropped, these areas could be deregulated in 2010 if they initially had three POs and at least one additional PO forecast. The remaining 42 exchange areas were not deregulated. These areas had three POs present and no PO forecast. To disentangle the forecast effect from the deregulation effect, we estimate separate effects for exchanges that were deregulated in 2008 and those deregulated in 2010. The binary variable for deregulation in 2008 captures the pure deregulation effect, whereas the indicator for deregulation in 2010 captures both effects. The difference between the two estimators is thus the forecast effect.

The estimates are shown in Column (5) of Table 5 and imply, as expected, that the pure deregulation effect from 2008 is smaller than the estimate from 2010 that captures both effects. According to our point estimates, upon being deregulated, an exchange area gains 0.22 additional LLU operators, whereas the forecast effect is about 0.24 LLU operators, the difference between the two coefficients. At 340 observations, the sample is unfortunately small and therefore the point estimates of the deregulation effect as well as the forecast effect - even though economically important — are not statistically significant on conventional levels. 


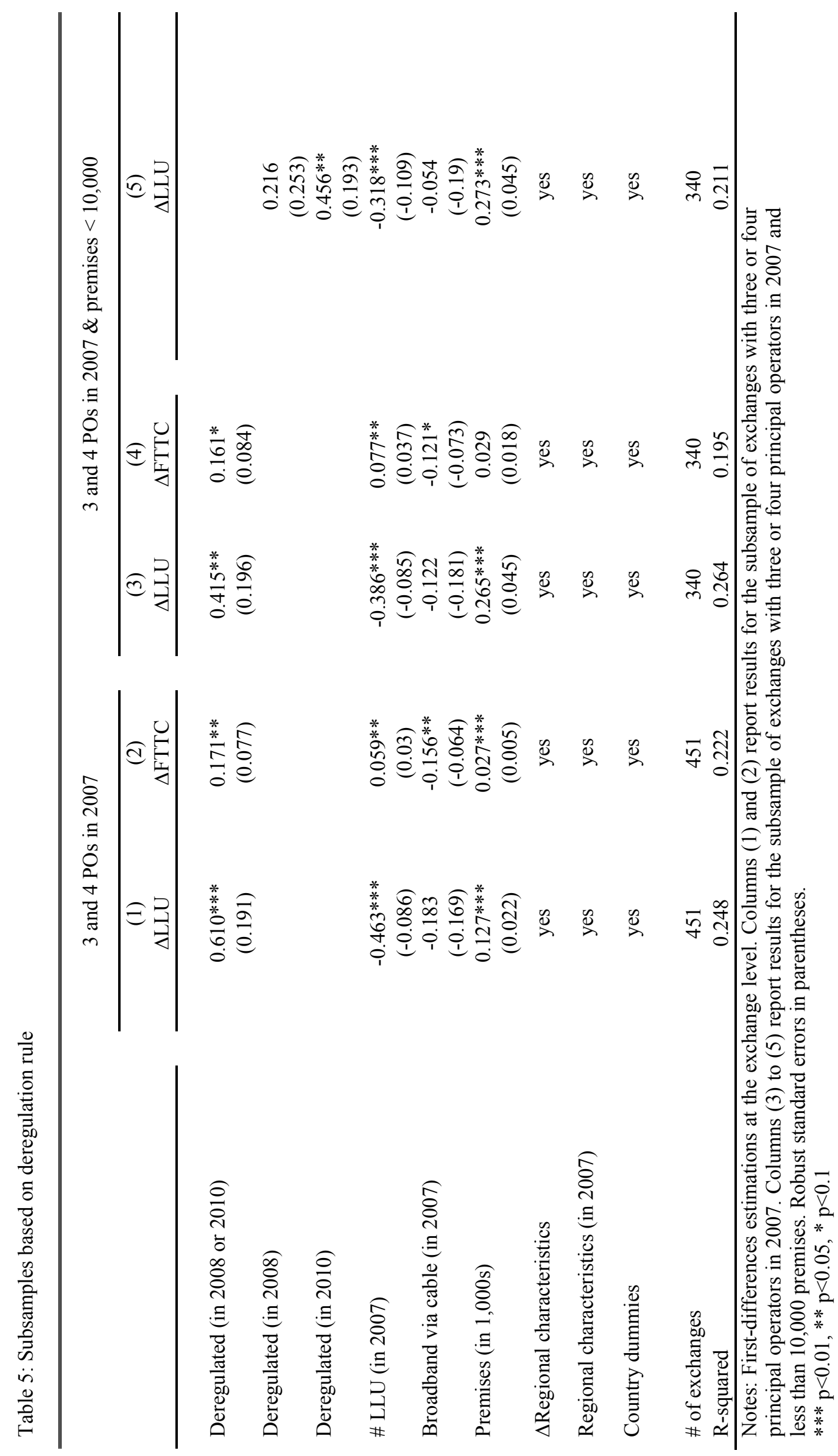




\section{Conclusion and Outlook}

This study provides first empirical evidence on the relationship between local deregulation and subsequent competitive development in the WBA market. Although to date theoretical predictions about competition-related developments in deregulated local markets have been unclear, our findings shed some light on this "black box." Our estimates imply that local deregulation of the U.K. WBA market has a positive effect on infrastructure-based investment by both the incumbent and its competitors. Upon being deregulated, every exchange gains at least 0.22 additional LLU operators. Moreover, after deregulation, the probability that the incumbent rolls out FTTC infrastructure increases by at least 16.1 percentage points.

We cannot observe counterfactual outcomes, i.e., we do not know with certainty how deregulated markets would have developed in the absence of deregulation. But given that our first-difference approach accounts for time-invariant exchange area characteristics, and that we also control for initial pretreatment conditions in 2007 , we are confident that our results reflect the counterfactual effect very well. This is corroborated by the fact that we find positive effects of deregulation in all subsamples and for all alternative specifications. In addition, our LLU operator estimates are not confounded with forecast effects that would bias our results.

These findings have important policy implications. The data reveal no negative effects on infrastructure-based competition in response to deregulation of competitive areas. On the contrary, our study shows that deregulated areas exhibit even higher levels of competition after deregulation. This finding should mitigate, at least to some degree, regulator concerns that competition will weaken when competitive exchange areas are deregulated.

Debate over the pros and cons of local deregulation of the WBA market is a recent development. We chose to study the effects of local deregulation of the British WBA market because the United Kingdom was the first country to take this step. This allows us to study the medium-term effects on the investment behavior of British Telecom and its competitors. We are confident, however, that the effects are generalizable to other countries. It is beyond the scope of our analysis to study longer-term effects such as how increased infrastructure-based competition will affect consumer prices and choice. Studying these effects provides a fruitful avenue of further research. 


\section{References}

Bourreau, Marc and Dogan, Pinar (2004), "Service-based vs. facility-based competition in local access networks." Information Economics and Policy, Vol. 16:2; pp. 287306.

Bundesnetzagentur (2010), Breitbandzugang für Großkunden: Marktdefinition und Marktanalyse des Marktes Nr. 5 der Märkte-Empfehlung der EU-Kommission vom 17. Dezember 2007.

EC (2007), Comments pursuant to Article 7(3) of Directive 2002/21/EC: Wholesale broadband access in the UK (UK/2007/0733).

EC (2008a), Telecoms: Commission approves Ofcom proposal to deregulate part of UK broadband market. Reference: IP/08/232.

EC (2008b), Comments pursuant to Article 7(3) of Directive 2002/21/EC: Wholesale broadband access in Portugal (PT/2008/0851).

EC (2008c), Comments pursuant to Article 7(3) of Directive 2002/21/EC: Wholesale broadband access in Austria (AT/20085/0757).

EC (2008d), Comments pursuant to Article 7(3) of Directive 2002/21/EC: Wholesale broadband access ("WBA") in Spain (ES/2008/0805).

EC (2008e), Comments pursuant to Article 7(3) of Directive 2002/21/EC: Wholesale broadband access in Finland (FI/2008/0848).

EC (2010) Comments pursuant to Article 7(3) of Directive 2002/21/EC: Wholesale broadband access in Romania (RO/2010/1102).

EC (2012a), Opening of Phase II investigation pursuant to Article 7a of Directive 2002/21/EC as amended by Directive 2009/140/EC: Wholesale broadband access market in Poland (PL/2012/1311).

EC (2012b), Comments pursuant to Article 7(5) of Directive 2002/21/EC: Wholesale broadband access in the Czech Republic (CZ/2012/1322).

Edina (2012), Boundaries of 2001 Census ST wards/electoral divisions (for standard tables) for England, Wales, Scotland. Available from: http://edina.ed.ac.uk/ukborders/.

Kiesewetter, Wolfgang (2011), "Die Empfehlungspraxis der EU-Kommission im Lichte einer zunehmenden Differenzierung nationaler Besonderheiten in den Wettbewerbsbedingungen unter besonderer Berücksichtigung der Relevante-MärkteEmpfehlung." WIK Diskussionsbeitrag, Nr. 363.

NOMIS (2012), UK Labour Market Statistics: Claimant count statistics at ward level for years 2007-2010. Available from: www.nomisweb.co.uk. 
Northern Ireland Statistics and Research Agency (2012a), Boundaries on 2011 Northern Ireland super output areas (SOAs). Available from: http://www.nisra.gov.uk/geography/.

Northern Ireland Statistics Research Agency (2012b), Ward-level population estimates for years 2007-2010. Available from: www.nisra.gov.uk.

OECD (2010), "Geographically segmented regulation for telecommunications." OECD Digital Economy Papers, no. 173, Paris.

Ofcom (2008), Review of the wholesale broadband access markets: Final explanatory statement and notifications. Publication date $21|05| 2008$.

Ofcom (2010), Review of the wholesale broadband access markets: Consultation on market definition, market power determinations and remedies. Statement Published $03|12| 10$.

Office for National Statistics (2012), Ward-level population estimates for years 20072010. Available from: www.ons.gov.uk.

Samknows (2007), Data on UK broadband availability in 2007. Available from: www.samknows.com.

Samknows (2012), Data on UK broadband availability in 2012. Available from: www.samknows.com. Scottish Neighborhood Statistics (2012), Ward-level population estimates for years 2007-2010. Available from: www.sns.gov.uk.

Stumpf, Ulrich (2010), Die Abgrenzung subnationaler Märkte als regulatorischer Ansatz. WIK Diskussionsbeitrag Nr. 334. WIK, Bad Honnef.

Weizsäcker, Carl C. von (2008), Regionalisierung der Regulierung im BitstromzugangsMarkt? ZEI Discussion Paper C189.

Woroch, Glenn A. (2002), "Local network competition." Handbook of Telecommunications Economics, vol. 1, ed. Cave M., Majumdar S., and Vogelsang I. Elsevier Publishing, pp. 641-716. 


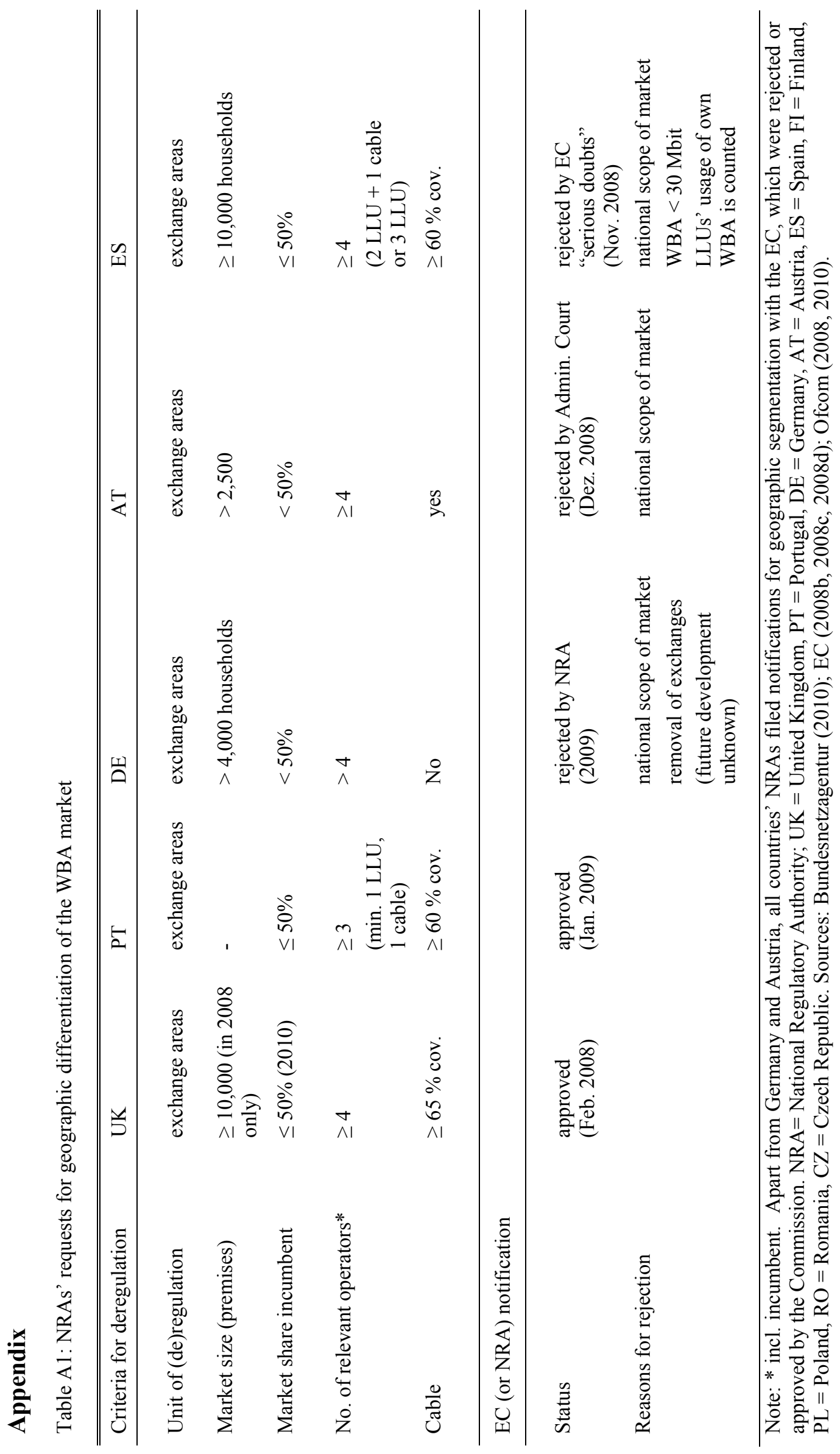




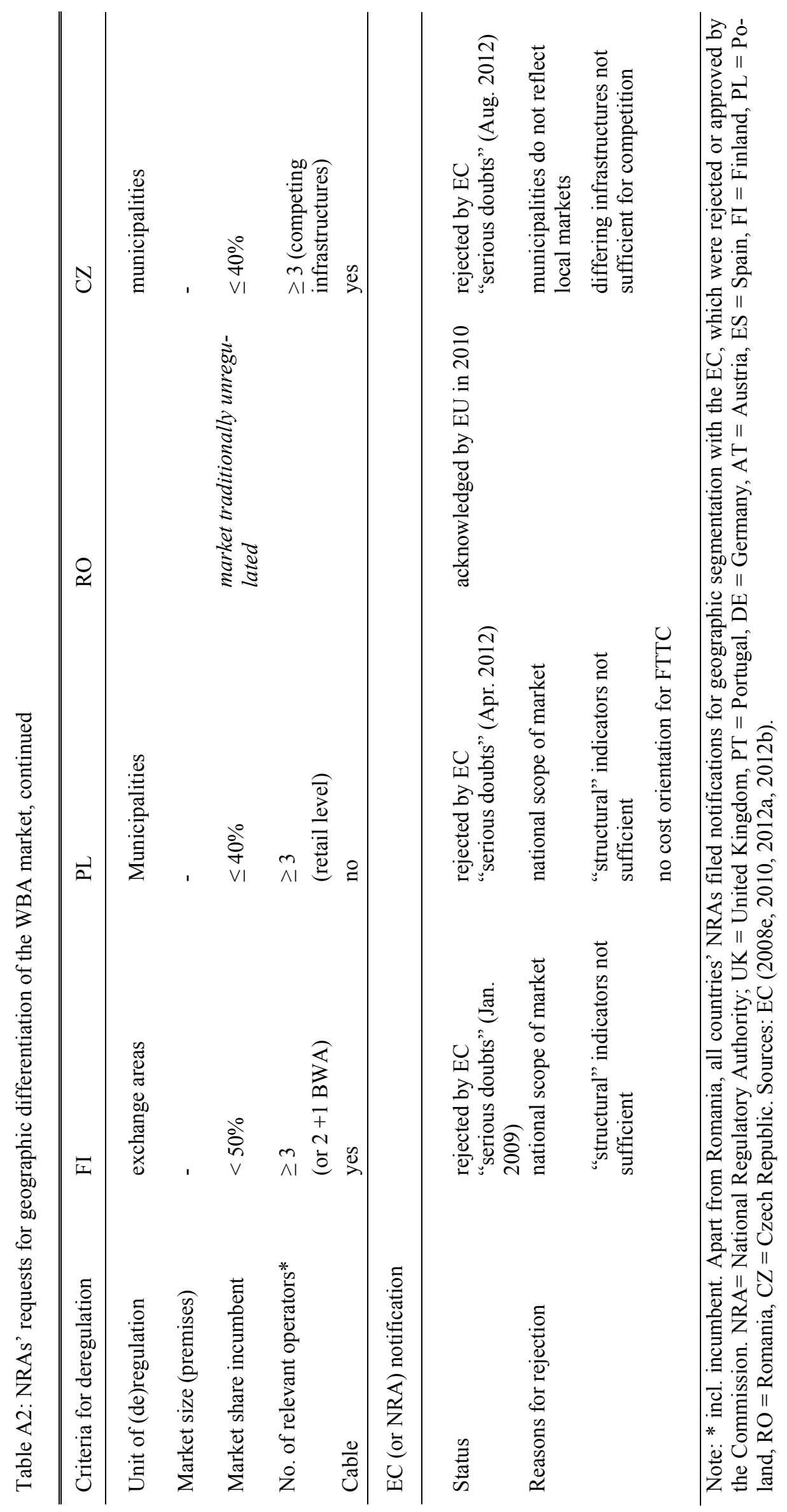


Table A3: Summary of the WBA market definitions by Ofcom in 2008

\begin{tabular}{|c|c|c|c|}
\hline Market & Description & Exchanges & Coverage \\
\hline Market 1 & $\begin{array}{l}\text { those geographic areas covered by exchange areas where BT } \\
\text { is the only operator }\end{array}$ & 3,658 & $16.4 \%$ \\
\hline Market 2 & $\begin{array}{l}\text { those geographic areas covered by exchange areas } \\
\text { where there are } 2 \text { or } 3 \text { principal operators present } \\
\text { (actual or forecast) AND exchange areas where there are } \\
\text { forecast to be } 4 \text { or more principal operators but } \\
\text { where the exchange serves less than } 10,000 \text { premises }\end{array}$ & 747 & $16.8 \%$ \\
\hline Market 3 & $\begin{array}{l}\text { those geographic areas covered by exchange areas where } \\
\text { there are currently } 4 \text { or more principal } \\
\text { operators present AND exchange areas where there are } \\
\text { forecast to be } 4 \text { or more principal operators but } \\
\text { where the exchange serves } 10,000 \text { or more } \\
\text { premises }\end{array}$ & 1,193 & $66.8 \%$ \\
\hline
\end{tabular}

Source: Ofcom (2008, p. 29); own calculations based on Samknows data.

Table A4: Summary of the WBA market definitions by Ofcom in 2010

\begin{tabular}{|c|c|c|c|}
\hline Market & Description & Exchanges & Coverage \\
\hline Market 1 & $\begin{array}{l}\text { exchange areas where only } \mathrm{BT} \text { is present or forecast to be } \\
\text { present }\end{array}$ & 3,396 & $11.2 \%$ \\
\hline Market 2 & $\begin{array}{l}\text { exchange areas where two principal operators are present or } \\
\text { forecast AND exchange areas where three principal operators } \\
\text { are present or forecast but where BT's share is greater than or } \\
\text { equal to } 50 \text { percent }\end{array}$ & 661 & $9.9 \%$ \\
\hline Market 3 & $\begin{array}{l}\text { exchange areas where four or more principal operators are } \\
\text { present or forecast but where BT's share is less than } 50 \text { per- } \\
\text { cent }\end{array}$ & 1,541 & $78.9 \%$ \\
\hline
\end{tabular}

Source: Ofcom (2010, p. 14); own calculations based on Samknows data. 


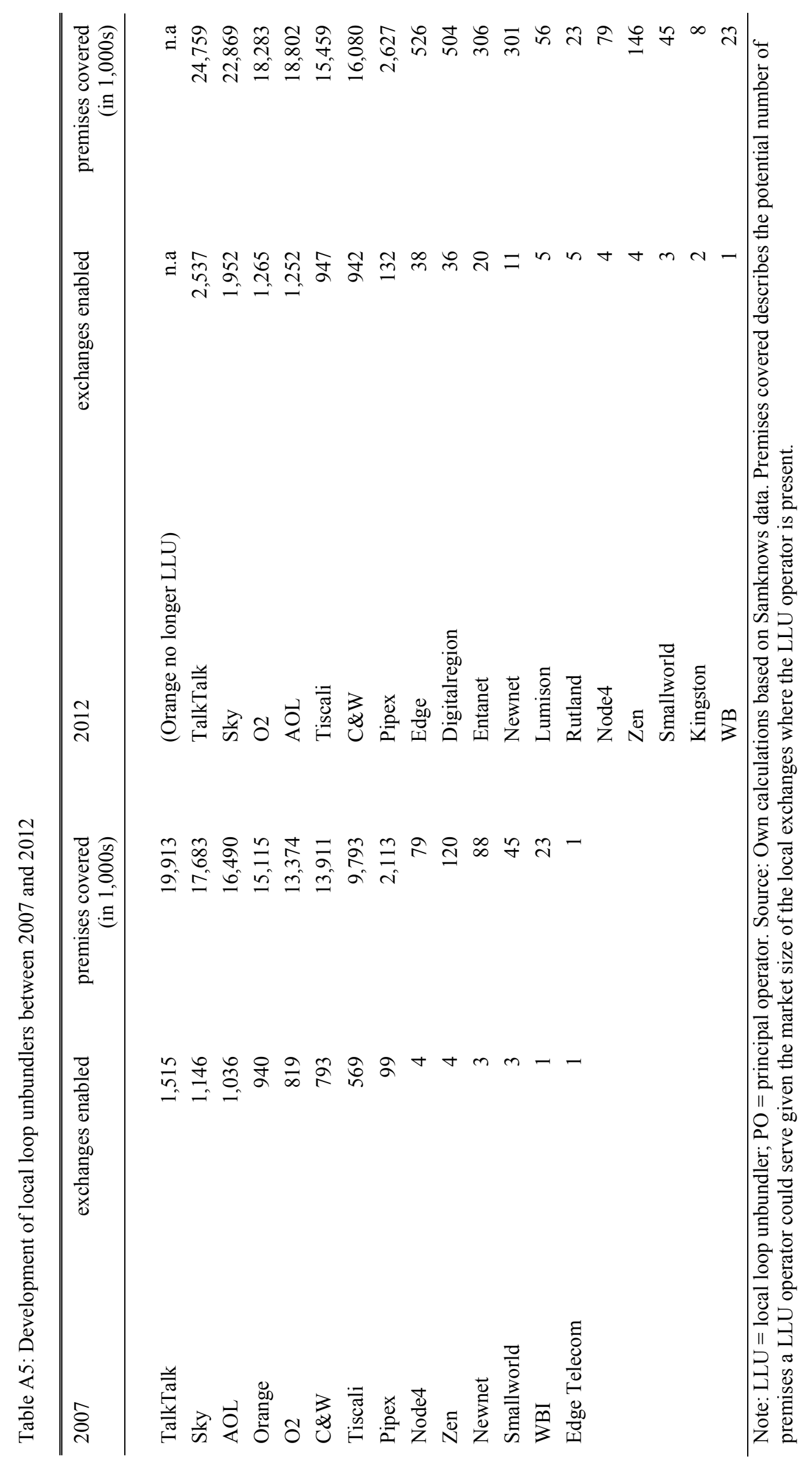

